Article

\title{
Cities in Sustainability Transitions: Comparing Helsinki and Istanbul
}

\author{
Anna Kuokkanen ${ }^{1, *}$ and Mahir Yazar ${ }^{2}$ \\ 1 School of Energy Systems, Lappeenranta University of Technology, Saimaankatu 11, 15140 Lahti, Finland \\ 2 Institute of Environmental Sciences, Boğaziçi University, 34342 Bebek/Istanbul, Turkey; \\ mahir.yazar@boun.edu.tr \\ * Correspondence: anna.kuokkanen@lut.fi; Tel.: +358-449-884-219
}

Received: 16 February 2018; Accepted: 26 April 2018; Published: 3 May 2018

\begin{abstract}
Systemic sustainability transitions are manifested as the needed scope to meet sustainability challenges at the local and global scales. While sustainability transitions are ubiquitous, each transition is nested in a specific spatial context. Especially, due to accelerating urbanization, cities are increasingly important agents, but they are also understudied geographical loci of change. Urban transitions are interesting because they operate at both the national and global scales, concentrating people, wealth, and resources. They have both regime and niche elements, as they act as an incubation space for novel experiments, ideas, and alternative social movements. Thus, this paper aims to improve understanding of the geographical context and spatial scales from a multilevel perspective and develop a framework for analytic comparison. Furthermore, the paper draws insights from two empirical cases, namely the cities of Helsinki and Istanbul. Consequently, opportunities and challenges for instigating context-specific sustainability transitions can be identified.
\end{abstract}

Keywords: sustainability transition; urban transition; multi-level perspective; energy efficiency; geo-spatial scales

\section{Introduction}

The urban sustainability transition has become essential for achieving global sustainable development goals, since it is expected that, by 2050 , more than $70 \%$ of world's population will live in cities [1]. Continuing urbanization is not only a socioeconomic phenomenon, but it also represents a great human ecological transformation [2]. Urban transitions are interesting in terms of sustainability transitions for several reasons, as follows: (1) the city scale can provide insight into dynamics between city and national regimes in relation to the landscape pressures; (2) cities are natural incubation spaces comprising novel and alternative niches; and (3) cities are increasingly concentrating the available power and resources, hence becoming more central actors for sustainability transitions at the transnational scale. Considering that cities account for $60-80 \%$ of energy consumption and generate as much as $70 \%$ of the human-induced greenhouse gas (GHG) emissions-primarily due to fossil fuel consumption [3] - the fast realization of residential buildings' emissions reductions can significantly contribute to sustainability. Hence, our aim is to compare two cities from different geographical and socioeconomic contexts-Helsinki and Istanbul—in terms of their energy efficiency targets in residential buildings. The two cities vary in several respects. In terms of size, Helsinki is a medium-sized European capital, while Istanbul is a megacity on the border of Eurasia. Socioculturally, Helsinki is a highly industrialized, Northern European city, while Istanbul is a highly dynamic and rapidly developing cultural melting pot. At the same time, socioeconomically, both cities can be viewed as drivers and trendsetters of their national economies. With comparative analysis, we aim to shed light on the following research questions: 
1. How does the city-scale regime interact with the state-scale regime in terms of energy efficiency in residential buildings? Are cities the drivers of sustainability transitions at the global and national scale, or do they reproduce and reinforce the national regime?

2. Do cities provide a nurturing environment for new niches that contribute to energy efficiency? If so, how?

\section{Cities and Sustainability Transitions}

\subsection{Sustainability and Cities}

Cities concentrate people, wealth, ideas and innovation [4], but at the same time, they are responsible for the associated energy, material, waste, and emission flows. Concentration is enabled by the global trade of goods, and consequently, the global appropriation of environmental resources and ecosystem services [4,5]. From a sustainability perspective, on the one hand, cities face tremendous challenges, including mobility, housing, energy, and food demand. On the other hand, they provide incubation spaces for novel ideas, technological niches, and social movements that can trigger systemic regime shifts [6]. On the other side of the equation is usually the assumption that greater technological development and economies of scale can reduce the environmental pressure per capita. It has been shown that increasing urban density generally reduces energy consumption [7]. However, there is also the rebound effect triggered by increasing productivity, where increased productivity generates more affluence, and growth of affluence tends to increase overall consumption and material throughput rather than decreasing it $[8,9]$. Hence, more attention to how cities can leverage the former in comparison with the latter is needed.

The role of cities in systemic change for sustainability has been studied in various, yet fragmented accounts, with theoretical roots in economic geography, political ecology, planning studies, and sociology [10]. Especially in terms of empirical research, there is a need for comparative studies that go beyond qualitative case studies and include quantitative analyses of larger urban datasets [10]. Such comparative studies can provide a more thorough understanding of key context-specific variables in sustainability transitions, shed light on different transition dynamics, and hence, pinpoint context-specific leverage points. Cities' environmental impacts depend on how they organize sociotechnical functions, such as mobility, housing, sanitation, waste management, and energy and food services [11]. However, cities are not islands. First, their sociotechnical regime, that is, the way energy or food systems function, depends to some extent on the national regime. Second, through global trade, cities draw and exchange resources from all around the globe. Third, cities cooperate and compete with other global cities for skilled people, investment, and livability. In this study, our aim is to analyze cities' potential to promote sustainability transitions by exploring several dynamics, as follows: (1) the city regime within the national-scale regime; (2) the city regime's interaction in global city networks and (3) the city's nurturing environment for niches. Moreover, by conducting a comparative study of two geographically disparate contexts-Helsinki in Finland and Istanbul in Turkey-our aim is to draw attention to spatial scales that have been largely neglected in the sociotechnical transition literature [11], by conducting a comparative study of two geographically very different contexts. In the Finnish and Turkish cases, the focus is on the energy-efficiency transition in the housing sector.

\subsection{Cities from the Multilevel Perspective}

The multilevel perspective is a mid-range theory about how radical sociotechnical system transitions occur via a multilevel interplay [12]. As such, it has been one of the most cited and used analytic and normative frameworks in sustainability transition research $[10,13]$. The multilevel perspective portrays structural change as an interaction between novel niches and incumbent sociotechnical regimes, which are both affected by the external landscape level. The regime represents the prevailing system structure, including technical artefacts, infrastructure, markets, user preferences, 
policy and science, associated incumbent actors, and social norms [12]. The regime level depicts the mainstream of system functioning, reinforced by its path-dependent nature [13]. Hence, when the landscape level generates a range of different pressures on the regime functioning, the regime level tends to follow the prevailing trajectory and adapt to pressures through incremental improvement and innovation [12]. In contrast, the niche level has a less coercive rule structure, as well as less rigid networks and alignments; hence, it is better suited for developing and testing more radical novelties in response to landscape pressures. When the pressure faced by the regime grows strong enough, windows of opportunity can open and enable niches to break out and replace the incumbent regime. This is the basic logic, but in practice, transitions naturally take different forms and follow different paths [14].

The multilevel perspective gives a structural-functionalist account of sustainable system change, focusing on large-scale patterns and rule structures [15]. As such, it has been criticized for its vagueness and subjectivity in defining and articulating the sociotechnical system and its boundaries [16]. Many retrospective transition analyses have focused on how fulfilling certain functions has transformed mainly in terms of technology—-for example, from sail to steam ships, from horse-drawn carriages to automobiles-as well as the associated infrastructure. However, in urban transitions, in which the subject of study is a city, defining the regime is less straightforward [17]. Cities can have a multitude of different neighborhoods (high-density, low-density, central, peripheral, etc.), building types (high-rise, low-rise, apartments, detached houses, etc.), and infrastructural components in one city [17]. Therefore, one could identify several subregimes operating and overlapping in one citywide regime, or the city regime can be perceived as multisegmented, consisting of contrasting pathways being developed simultaneously, such as public transportation, road capacity expansion, and bike lanes [17]. In addition, urban transitions have elements of niche experiments, social movements and alternative lifestyles, and city-space is often perceived as an incubation space for sociotechnical innovations and transformative action [18]. Thus, cities can be accounted for in several ways from a multilevel perspective.

In addition, cities are in constant flux as they grow and develop, and new socio-technical artifacts are added to the old ones. Especially, due to the continuing urbanization, new arising challenges, and growth of awareness, cities seem to have regained aspirations to take 'matters into their own hands' and exploit urban development as a purposive action toward more sustainability [19]. Sustainability can be a driving motive for urban development and justification for choices being made, or it can merely be a pretext to receive untapped investment funds. There may also be competing strategies and views about what sustainability transition implies and contains in a specific city, for example, higher house density or more green areas. Therefore, in terms of the sociotechnical system transition, the interest lies in which changes enable more sustainability and which lead in the opposite direction [17], and the extent to which these are context specific. From the multilevel perspective view, it becomes essential to allow for a more fragmented account of the geographically determined regimesubregimes that are operating in a city-regime, but are not necessarily geographically limited to the city boundary.

\subsection{Spatial Scales in Sustainability Transitions}

Although transitions usually occur in a specific geographical context and scale, the spatial dimensions have largely been ignored in sustainability transition research [11]. The spatial scale is usually treated implicitly in the multilevel perspective, and often, there is emphasis on national scale transitions [11]. This is a severe limitation for analyzing urban transitions and the role of cities in their national contexts. Depending on the situation and context, cities can be perceived as subregimes subject to the national-scale regime, or active actors, developing strategies and transition initiatives that are then taken up by the national context. In other words, cities can shape or be shaped by national transitions [17]. City-scale regimes can have extremely differentiated transformation trajectories due to regionally varying effects from landscape forces and differential resources to accommodate these 
pressures [20]. City regimes can translate landscape pressures according to their adaptive strategies and the resources available in the regime [21], which can be significantly different from the adaptive strategy of nation-level regime. In effect, cities and national-level regimes can have complementary, but also competing, transition pathways. Hence, the lack of attention to institutional embeddedness in the multilevel perspective can hinder the understanding of sustainability transformations [11].

New sociotechnical configurations may potentially span different scales and connect distant places [11]. With the existing possibilities of social media, digitalization, and big data, new sociotechnical configurations seem to emerge in global communities rather than as strictly local initiatives. Especially, consumer-oriented innovations with new business models-such as Uber or Airbnb-travel faster across global cities than changes in the national regimes from which they emerge. Such transformations are often uncoordinated and organic, and hence, they are not necessarily driven toward a predefined goal and shared vision. Yet, more startups are motivated explicitly by a desire to solve current social and environmental challenges [22]. Cities are also involved in transnational networks, in which they exchange ideas, formulate common urban visions, and translate sustainability pathways [23]. These networks can be influential in both internal and external governing, and thus, override nation-state governing [23,24]. Therefore, the emergence and alignment of new niches can occur as a global phenomenon and travel as a global niche before it manages to transform the local regime.

\section{Methodology}

To answer the research questions, we use comparative case studies. In our research, Helsinki and Istanbul are selected as they offer sustainability transition through energy efficiency targets to leverage the impact of housing sector to climate change. If the national energy efficiency agendas of the two countries are achieved, the carbon footprint of the two cities could potentially be reduced in the long term, which eventually accelerates sustainability transition in Helsinki and Istanbul.

Comparative case studies are widely used in transition studies, for instance, in researching sustainable grassroots innovation [25], long-term transition pathways studies [26], and innovations in urban climate adaptation [27]. A single case study may help to identify and trace underlying mechanisms, but it may suffer from a lack of justification and implication beyond the immediate case. Comparative analysis helps to test an analytical framework and to improve confidence in drawing conclusions [28]. In addition, empirical research shows that transformative responses to climate change differ between global megacities [29] and different socio-economic and socio-political contexts. Thus, comparative studies offer more global analytical approach [30]. Herein, our aim is to highlight the scalar and the contextual factors influencing on sustainability transitions towards energy efficiency of housing.

We used a comparative case study approach, in which we constructed cases based on quantitative and qualitative data related to energy efficiency regimes in the housing sector at the city level and the national level. Energy efficiency regimes consist of producers, which include developers, construction companies, utility services, authorities, public planners, consumer-residents, policymakers, financiers, technological companies, and research and development organizations. To analyze energy efficiency transition, we used several qualitative and quantitative indicators. As quantitative indicators, we looked at the primary and final energy use, and carbon emissions at the housing sector over time. We also looked at factors-such as building stock, energy performance certification, and living space area-that can explain changes in the overall energy efficiency. We also looked at the strategic actions and commitments, including practical measures, which promote the regime's transition to higher energy efficiency.

The two cities share some similarities; yet they exist in very different geographical contexts. Both cities can be undoubtedly be called the socioeconomic and sociocultural powerhouses in their nation-states. Therefore, they are also the natural loci of sustainability transitions. Nevertheless, they have many obvious differences that may shed light on the differentiated transition dynamics. 
Helsinki is a rather small Nordic capital $(0.6$ million, $11 \%$ of the Finnish population, but in the metropolitan area, 1.5 million and $27.7 \%$ ), whereas Istanbul is a fast-growing metropolis on the border of Eurasia (14.8 million, $18.5 \%$ of the Turkish population). The Helsinki metropolitan area represents $31 \%$ of overall employment and $37 \%$ of the national gross domestic product (GDP) in Finland [31], while Istanbul creates $30.5 \%$ of Turkish GDP [32]. The cities' environmental impacts can be analyzed through the ecological footprint (EF), which measures the overall environmental appropriation based on the final consumption of goods and services [2]. The ecological footprints of cities, as well as nation states, tends to grow with the growth of affluence [33]. The more affluent the city, the smaller the relative share of food consumption and the greater the relative share of energy-intensive goods and services [33]. For example, in terms of food consumption, Helsinki and Istanbul have similar ecological footprints, at about 1.5 and 1.2 global ha/cap, respectively. The biggest difference is in the carbon footprint, which is almost three times bigger in Helsinki. Interestingly, Istanbul's ecological footprint remained constant in the period of 2010-2015, whereas Helsinki managed to reduce its GHG emissions, from almost 4000 to below $3500 \mathrm{kt}$ carbon dioxide equivalent $\left(\mathrm{CO}_{2}-\mathrm{e}\right)$ in 2007-2012 [34]. Furthermore, Istanbul's per capita EF is 0.67 gha higher than that of Turkey $(+26 \%)$ [5], whereas Helsinki's per capita EF is 0.9 gha lower than that of Finland (-13\%) [35]. This can be due to differences in calculations, yet it suggests a need to look deeper into the dynamics of city and state regimes.

Throughout the research, we collected data from a range of official documents related to energy efficiency and climate change in Finland and Turkey, focusing specifically to Helsinki and Istanbul in order to assess cities-national regime dynamics and cities-global networks relations.

We collected both quantitative and qualitative data to construct in-depth comparative cases. Quantitative data was used to provide an overall picture of the housing sector in each city and in relation to its respective national context, particularly in terms of energy use, the associated greenhouse gases and energy efficiency categorization. If possible, we have looked at the longitudinal data to see whether there are signs of sustainability transition that is, decreasing greenhouse gases generated in the housing sector. The qualitative data has been used to map out the role of a city, as an organizational as well as administrational entity, in facilitating and promoting sustainability transition. We have aimed to analyze the role of cities through three different dynamics, which all can affect the direction and pace of multi-level change. The main data sources for Turkey and Istanbul are: [36-39]. The sources for Finland and Helsinki are: [40-43] and national and regional authorities related to energy efficiency in the housing sector. These documents allowed us to see the countries and cities' visions and pathways to achieve energy efficiency and climate change efforts, which eventually guided us to assess the degree in which these vision and pathways are followed by looking at what is implemented on the surface of the national and local regimes, niches, and their global environment. In addition, media coverage was investigated and analyzed to provide up to date information about the current implementations of energy efficiency in housing sector in both countries and cities. Media coverage is embedded throughout this paper, as they gave hinted at comparisons between what has been said by the politicians or international donors in terms of sustainability enhancement and energy efficiency. For instance, through media coverage, we have seen that the first election of the mayor of the city of Helsinki has been active in establishing both intra-city networks and committing to the international ones. For Turkey's case, we have also seen that-through media coverage-Istanbul is given a special role to become a global city, which is compatible with the national government's 2023 vision to become world's 10th largest economy.

We also collected data through semi-structured interviews with seven start-up companies in Istanbul in order to support our discussion in cities-emerging niches. All the selected start-ups are founded since the past 2-3 years and based at an incubator, known as TechnoParks, at the Istanbul Technical University and Yildiz Technical University in Istanbul. The start-ups aim to have a substantive function in the housing sector of Istanbul for energy savings and efficiency in buildings. Thereof, our semi-structured interviews with the heads of seven start-ups' entrepreneurs focused on: (1) to what extent they can be collaborating with the city-regime in order to implement their innovative 
ideas to the on-going urban renewal process in Istanbul; (2) what are the current political-social and economic factors that hinder the entrepreneurs in creating a viable alternative to the city regime. To supplement this interview data, additional data was gathered from a variety of sources in emerging niches in Helsinki-such as company information, publicly available sources on businesses, and media reports-to compare emerging niches between the two cities. It should be mentioned here that Helsinki's nurturing environment for start-ups is pretty well advanced in comparison to Istanbul's case, and its positive impact has already been observed in the city environment. Thereof, we relied on the outcomes that can be observed at the niche level.

\section{Cities in Sustainability Transitions: Helsinki and Istanbul}

Due to the growing consumption of energy-intensive goods and services, improving energy-efficiency is one of the lowest hanging fruits in terms of reducing the overall environmental impact. Energy efficiency represents about $40 \%$ of the GHG-reduction potential that can be realized at a cost of less than $€ 60$ per tonne of carbon dioxide equivalent [44]. The building sector represents $40 \%$ of the energy consumption in the European Union, where two-thirds of the constructions were built before energy performance standards were put in place, and their renovation rate is only around $1 \%$ per year [45]. In Turkey, households consume 22.3\% (19.1 Million tonnes of oil equivalent (Mtoe)) of the final energy consumption (85.5 Mtoe), but in contrast to Europe, urban renewal is pervasive and fast paced in this country. In the European Union and Organization for Economic Co-operation and Development (OECD) countries, energy efficiency has already been promoted and enforced with various policies since the 1970s [45]. In recent years, the European Union has strived to establish more ambitious targets and promote systemic and consumer-oriented transitions to carbon neutrality. In 2016, the European Commission proposed an update to the Energy Efficiency Directive, including a new target of $30 \%$ energy efficiency by 2030 [46]. The proposal includes an update to the Energy Performance of Building Directive and launch of smart finance for smart buildings initiative [46].

\subsection{Energy Efficiency in the Housing Sector in Finland and Helsinki}

Finland, among other Nordic countries, is often treated as a global model country in terms of decarbonizing the energy system. Its long-term goal is to achieve a carbon-neutral society by 2050, and its strategy relies on the four pillars of renewable electricity and heat, energy efficiency, transportation, and industry [47]. As a Nordic country, with long winters and a low population density, the energy use per capita is higher than the average in OECD countries. Space heating represents the largest end use (nearly 70\% of households' total energy consumption), the average Nordic building stock consumes $126 \mathrm{kWh}$ per square meter-12\% higher than the European Union average [40]. Space heating represents $68 \%$ of total energy consumption of households, $15 \%$ goes to heating water, $5 \%$ to heating saunas, and less than $13 \%$ to house devices, cooking, and lighting [42]. Hence, energy efficiency plays an instrumental role in the climate policy and the de-carbonization of the housing sector. Although the heat requirements per buildings have decreased, overall emissions continue to increase due to the growing building stock, growing size of apartments and office buildings and growing use of electronic devices [43]. The final energy demand in housing has grown nearly $30 \%$ since 1990, representing $333 \mathrm{PJ} / \mathrm{a}$ (2013) [42]; however, after peaking at 26,890 kWh/a in 2003, total energy demand per Helsinki resident has decreased to 23,442 kWh/a in 2015 [48].

Finland is subject to the European Union's energy efficiency target of $27 \%$ by 2030, but many sectors, cities, and municipalities have set more ambitious targets. In 2012, the European Union imposed an energy efficiency directive (2012/27/EU), which has been implemented in Finland since 2014, with the most recent amendments in 2017. Municipalities and industries have made voluntary energy efficiency commitments with the government since the 1990s [49]. Their voluntary nature and the focus on incremental improvement are seen as essential to their success among stakeholders [50]. In Finland, municipalities are relatively independent from the central government, and they have their own budgets, but they also have many constitutive obligations. In terms of energy efficiency, the city 
level has imposed voluntary energy conservation action in the buildings owned by the city; however, national-level policies for energy performance have also been implemented for other buildings [51]. The city can also have a partial influence through land use planning and city-owned utility companies, such as energy companies. Helsinki is the capital and the most populous city, and it became mayor-led in 2017. A shift from civil servants to a democratically elected mayor may imply some changes in the overall management of the city. At least so far, it seems that Helsinki wants to take a more active, progressive role in the urban sustainability transition than what the national regime imposes. The city of Helsinki has made several commitments for the de-carbonization transition, and energy efficiency is one of the key elements in this. The long-term commitment is achieving a carbon neutral city by 2050 .

When measured in square meters, the Finnish building stock consists of $41 \%$ detached houses, $33 \%$ apartment buildings, $16 \%$ commercial buildings, and 10\% public housing [42]. Most dwellings are privately owned, at $65 \%$, with $91 \%$ privately owned detached houses and $71 \%$ of apartments; furthermore, the private sector owns $20 \%$, municipalities less than $10 \%$ and the state around $1 \%$ [ 42 ]. Over half of the building stock was built after 1980. Urbanization has occurred in two waves, from the 1970s to the 1980s and after 2010, moving from the countryside to urban areas in an accelerated fashion. Since the 1970s, Finland has had some energy-efficiency requirements concerning buildings; in 2010, the insulation requirements in particular significantly increased. New buildings, or those built after 2010, are automatically more energy efficient. In older buildings, which are more critical, energy-efficiency improvements are usually implemented during the fundamental renovations that are required in 30-40 years. Privately owned houses implementing energy conservation measures during the renovation can receive monetary aids from the government [52]. While almost all new buildings fall under the energy-efficiency rating $B$ and $C$, almost all older buildings fall under $\mathrm{E}, \mathrm{F}$, and G. Energy consumption in the housing sector is described in more detail in Table 1.

Table 1. Energy Consumption in the Housing Sector [42].

\begin{tabular}{cccccc}
\hline & Single Houses & $\begin{array}{c}\text { Apartment } \\
\text { Buildings }\end{array}$ & $\begin{array}{c}\text { Commercial and } \\
\text { Public Buildings }\end{array}$ & Total (GWh/a) & Shares (\%) \\
\hline Electricity & 10,400 & 4200 & 1800 & 16,400 & 22 \\
District heating & 2400 & 17,000 & 12,000 & 31,400 & 43 \\
Heat pumps & 3800 & 300 & 300 & 4400 & 6 \\
Biofuels & 13,100 & 200 & 800 & 14,100 & 19 \\
Fossil fuels & 2900 & 1100 & 3000 & 7000 & 10 \\
Total (GWh/a) & 32,600 & 22,800 & 17,900 & 73,300 & 100 \\
Shares from energy & 44 & 31 & 25 & 100 & \\
consumption (\%) & 41 & 33 & 26 & 100 & \\
Shares of housing (\%) & 41 & & &
\end{tabular}

Geographically, Helsinki differs from the Finnish average, mainly because it is the most densely populated urban area in the country; the population density in Helsinki 2984.09 person $/ \mathrm{m}^{2}$, whereas the Finnish average is $17.64 \mathrm{p} / \mathrm{m}^{2}$. Therefore, the building stock is the opposite of the Finnish average, where detached houses are predominant. About $20 \%$ of the building stock was built before 1959, $30 \%$ in $1960-1979,28 \%$ in 1980-1999, and 22\% after 2000 [42]. The average living space has grown steadily since 1970, and it is about $40 \mathrm{~m}^{2}$ /person on average in Finland (in Helsinki, it is $34 \mathrm{~m}^{2} /$ person). However, with constructions from after 2010 — especially in apartment buildings—the average size has begun to decrease [42]. Housing represents almost half the carbon footprint per capita in Helsinki. While the total carbon footprint has decreased since 1990, energy consumption for housing has not decreased as significantly, as illustrated in Figure 1 [43].

The majority of startups and new businesses (over $40 \%$ of the national total) are concentrated to Helsinki metropolitan area [53]. This is of course due to natural advantages but also due to progressive support of the municipality. Helsinki metropolitan area has several universities with various startup platforms and supporting services, such as co-working spaces, accelerator programs, venture programs, and hubs. These services have increased in the recent years. Housing and 
construction sector represented almost a third of all growing startups in 2011 [53]. These are not all related to energy efficiency, but it still indicates that housing represents a significant share of all new business. Particularly an increasing amount of intelligent household appliances presents various ICT-based business opportunities. Whereas earlier energy efficiency was pursued mainly through technological investments, at present there are more businesses offering energy efficiency as a service (ESCO-Companies). There are also initiatives and crowdfunding projects that are focused on installing solar panels on the roofs of industrial buildings. Nevertheless, particularly in the urban area, where apartment buildings dominate, deputy landlords play a critical role in pursuing energy efficiency savings.

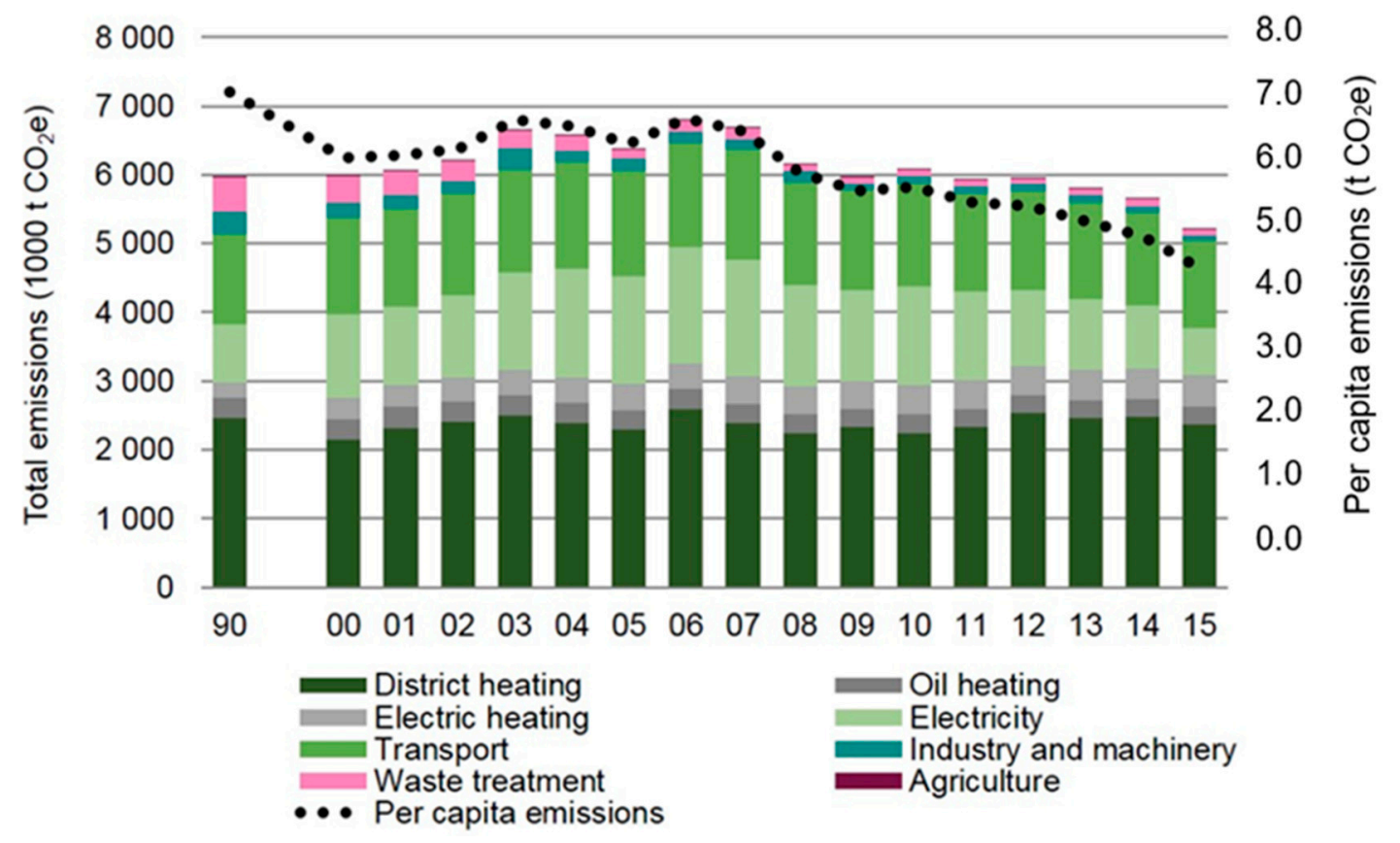

Figure 1. Greenhouse gas (GHG) emissions in the metropolitan area of Helsinki [43].

\subsection{Energy Efficiency in the Housing Sector in Turkey and Istanbul}

The Turkish economy is comparatively energy intensive in relation to those of other OECD countries [54], and the energy demand has been increasing over the last 15 years, since the country aims to become one of the world's 10 biggest economies by 2030 [55]. Thus, energy independence is a high priority for the Turkish government. Energy efficiency has been promoted by the International Energy Agency as 'hidden fuel', containing one of the highest potentials for climate change mitigation and adaptation globally. Moreover, the energy-efficiency policy and practices fit well with Turkey's future membership in the European Union [38,56]. Thus, Energy Efficiency Law no. 5627 was enacted in 2007 to promote energy efficiency throughout the various sectors in the country. For instance, in terms of final energy consumption, the industry sector represents the largest consumer, at $36.1 \%$, followed by the building sector, at $22.3 \%$ [36]. The building sector in Turkey presents significant opportunities for cost-effective energy and $\mathrm{CO}_{2}$ savings, estimated at some 30-50\% of the current levels [57]. In Turkey, there are no accurate data on the residential building stock; thus, following the data on the building permits, it is estimated that the current residential building stock comprises approximately 2.75 million $\mathrm{m}^{2}$ in floor area. This leads to an average floor space per capita of approximately $30 \mathrm{~m}^{2}$, which correlates with benchmarks from other comparable countries worldwide [58].

Along with the 2007 Energy Efficiency Law, Turkey has set up a regulatory and institutional framework to promote energy efficiency in buildings; the key components of this framework are the Building Energy Performance (BEP) Regulation and the 2011 Energy Performance Certificates 
(EPC). The EPC will be issued to all buildings by 2019, and the country aims to decrease the annual energy consumption in the buildings and premises of public institutions by $10 \%$ by 2015 and by $20 \%$ by 2023 [37]. The minimum $C$ level energy standard is mandatory for all existing buildings, and a prerequisite for new buildings is to be licensed [59]. Since 2011, new buildings have become more energy efficient than older ones. In Turkey, almost all buildings fall under the energy efficiency ratings $\mathrm{B}$ and $\mathrm{C}$, as detailed in Table 2.

Table 2. Number of Buildings with Energy Levels in Turkey and Istanbul [59].

\begin{tabular}{ccc}
\hline Energy Level & Turkey & Istanbul \\
\hline A & 2209 & 732 \\
B & 217,212 & 51,476 \\
C & 411,768 & 74,962 \\
D & 8573 & 1242 \\
E & 1775 & 110 \\
F & 497 & 29 \\
G & 673 & 62 \\
Total & 642,709 & 128,613 \\
\hline
\end{tabular}

There are also national acts and regulations that are compatible with the promotion of energy efficiency in buildings, namely the recently launched National Energy Efficiency Action Plan (NEEAP) for 2017-2023, Turkey's Climate Change Strategy and the National Climate Change Action Plan (NCCAP) 2011-2023. Since the action plan has been initiated, a professional network of green building and energy efficiency audit companies-including universities and domestic and international nongovernmental organizations (NGOs) - have emerged in Turkey, and especially in Istanbul, where the percentage of energy consumption and intensity of construction permits are the highest [60]. According to the latest Population and Housing Census (PHC) in 2011, in Turkey, there were $19,482,000$ households as of the research date [61]. Istanbul is the most populous province in Turkey, accommodating 3,699,930 households. In Istanbul, 60.6\% (67.3\% for Turkey) of the householders own their dwellings and $31.5 \%$ (23.8\% for Turkey) are tenants; those that live in dwellings owned by governmental or private organizations consist of $0.9 \%$ (1.5\% for Turkey) of households. Householders that are not owners of their dwellings, but do not pay any rent, represent $7 \%$ (7.3\% for Turkey) of households [61]. The construction sector constituted around 59\% of the gross fixed capital formation in Turkey in the first quarter of 2017, while it was $48.6 \%$ in the first quarter of 2009 [62]. As the construction sector still dominates Turkey's economic growth, considering the ongoing seismic risk-driven urban renewal process and energy efficiency, Istanbul may offer a sustainability transition with its dense construction activities going hand in hand with urban renewal. (The Marmara earthquake in 1999 prompted over a decade-long process toward implementing legislation and restructuring public agencies to ensure seismic resilience with the urban renewal process, which accelerated after the Van earthquake in 2011 and culminated in the 2012 'Law of Transformation of Areas under the Disaster Risks no. 6306'. Seismic risk then became essential for maintaining long-run growth in the construction sector.)

There are 39 municipality districts in Istanbul, each of which has its own governing structure; the municipalities are overseen by the Istanbul Metropolitan Municipality (IMM), which is run by the governing party. The IMM is responsible for the city's overall strategic and master plans and the approval body for the 39 districts' budgets, while the district municipalities take care of municipal services. From an initial review, the Istanbul Metropolitan Strategic Plan (IMSP) for 2015-2019 seems quite good, and it includes environmental and social concerns with a vision of making Istanbul sustainable and livable [63]. To be able to achieve this vision in the residential areas, the Metropolitan and district municipalities in Istanbul not only monitor the EPCs to provide building permits; rather, the IMM has also engaged Istanbul in several international initiatives to tackle the effects of climate change in the housing and many other sectors. For instance, the previous mayor was the president 
of the Global Network of Cities, Local, and Regional Governments (UCLG), and convinced Istanbul to become a signatory member of the Compact of Mayors and the C40, a group of cities aiming for greater action on climate change. Due to these international commitments, the IMM has been preparing the Istanbul Climate Change Action Plan since 2016, with the vision of creating a 'Climate Friendly City' [64]. The plan also highlights the importance of energy efficiency and green building standards in the residential areas of Istanbul for reducing GHG emissions and promoting energy savings. With respect to the district municipalities in Istanbul, there is evidence of more engagement with climate change and energy efficiency in buildings, at least on the surface.

Several energy-efficiency and green building audit companies, as well as international financial institutions and national and international NGOs in Istanbul, are taking an active role in pursuing sustainable and low carbon actions in the housing sector. The European Bank for Reconstruction and Development (EBRD) and Austrian Development Bank have provided energy-efficiency loans, which are transferred through Turkish Banks [65]. With this financial mechanism, the international financial institutions have entered the urban renewal process in Turkey and supported broadened energy efficiency in residential buildings. The energy loans are only received if the product is purchased and approved by the member company of the Association of Heat, Water, Sound, and Fire Insulators (IZODER). Moreover, 'insulation materials' are promoted as the most efficient way to achieve the minimum (C) energy standard, which has boosted the insulation material sector. The international green building certification schemes have also become essential in the Turkish market [66]. Globally known certification schemes, such as the BRE Environmental Assessment Method for housing (BREEAM), and especially, Leadership in Energy and Environmental Design (LEED), have become dominant in the Turkish market for green building certificates [67], and the numbers of certified buildings are increasing.

Along with these sectors' seemingly green credentials, there are some collaborations between the national government, international financial institutions and NGOs. The Turkish Green Building Council (Çevre Dostu Yeşil Binalar Derneği, ÇEDBíK), for instance, joined with the Ministry of Environment and Urbanization to develop the 2017 Green Building Regulation for Buildings and Settlements, a national green certification to compete with international green building certificates. The EBRD also collaborated with the Ministry of Energy and Natural Resources, and the European Union funded the 2017 NEEAP, which aims to reduce the primary energy consumption in Turkey by $14 \%$ by 2023 . The energy-efficiency law and enforcements have inevitably resulted in clustering of big and emerging businesses in Istanbul's housing sector, there is a growing start-up environment in the city that covers different types of services and technologies aiming to contribute to sustainability in the buildings, from the planning and commissioning process to the end of construction. The start ups in the field of energy efficiency have been predominantly founded in the past 2-3 years, and they are based at an incubator known as TechnoParks at Istanbul Technical University and Yildiz Technical University in Istanbul. They are supported through consultations with academics and experts in businesses. The Individual Young Enterprise (BIGG) capital support program—developed by the Turkish Scientific and Technological Research Council (TUBITAK) — provides grant support and technical assistance (from its academic board) to early start-up companies with innovative ideas.

\section{Results and Discussion}

\subsection{City-Nation-Regime Dynamics}

In the Finnish and Turkish energy efficiency in buildings cases, it seems evident that nationwide (and in Finland, EU-level) energy-efficiency policy creates an impetus for the urban transition toward sustainability, especially in terms of upgrading the energy performance levels of the housing sector. Indeed, city regimes are naturally embedded in the national production and consumption regimes; however, they cannot be treated simply in terms of a hierarchical relationship. The city of Helsinki has been more progressive in implementing some sustainable initiatives and policies, especially 
in consumer-oriented actions, than the national- and EU-level regimes have. In terms of energy efficiency, the city has made voluntary energy-conservation agreements, which are ahead of the EU and national actions [49]. Nevertheless, as most buildings are privately owned, decisions on implementing energy-conservation measures depend on the owners. Especially in older houses, where such measures can be taken up during major renovations, high investment costs can hinder their adoption. Although there are some energy-conservation aids, financial instruments specifically directed at energy savings and environmental conservation and solar panels for privately owned buildings must be developed further [51].

It can be argued that the national government in Turkey often makes important planning decisions, and indeed, decides on the overall direction of Istanbul, as it controls most of the municipality's funding; hence, the decisions are made without consultation and often override local decisions in the process. This results in the president wielding significant influence over the city $[68,69]$. This evidence seems to suggest that the lack of decentralization in Istanbul's local administration ultimately hinders the city's adaptive capacity to lead the sustainability transition without the national government's consent. The city's dependence on the national regime also undercuts its innovative capacity. Most entrepreneurs think that the strategic or master plans for Istanbul are often not followed or altered significantly by politicians; the lack of sustainable vision in Istanbul discourages them from further investment. Most of the entrepreneurs we engaged with expressed a sense of hopelessness about achieving a sustainable Istanbul. This is especially due to previous development resulting in poor-quality buildings and a lack of green spaces; urban renewal is now required, but this is driven by profit motives over creating a healthy, safe, livable city for all citizens. In addition, many entrepreneurs consider that their products would be a solution for ensuring greening the current and new residential buildings if they could forge personal ties with the local and national governments to facilitate their engagement in large-scale urban renewal projects in Istanbul.

\subsection{Cities and Global Networks}

It is often thought that cities are closer to their residents than the state is, but cities also seem to be 'closer' globally, through their networks, than states are. In terms of global action for climate mitigation and sustainability transitions, states seem to compete, whereas cities aim to cooperate [21]. Cities do so through transnational networks, where they are governed both internally in the network and externally, by establishing a shared vision. However, they also compete for talented human resources, financial investments, and residents' satisfaction. Naturally, all these areas are essential for supporting the sustainability transition. As Finland still has over 300 municipalities, the state level has been wary about treating bigger cities differently or concentrating too much power there. The public debate between centralization and pro-urban politics against spatial diversification is constantly flaming up. This is reflected by sociopolitical difference, as support for the Green Party in Helsinki and some other cities is significantly higher than the national average. Thus, with the first election of the mayor, city of Helsinki has been active in establishing both national intra-city networks and committing to the international ones. Helsinki is part of the Eurocities network, Covenant of Mayors on climate action, and ICLEI Local Governments for Sustainability, to name a few. In the recent strategy, Helsinki strives to become the most functional city, accelerate green growth, become the Nordic start-up hub, to join the C40 climate network, set more ambitious climate and sustainability goals than before and strengthen its interests in the national policy [70]. This demonstrates that the city level increasingly aims to deal with matters autonomously; yet, it is evident that Helsinki depends on national and European policies. Nevertheless, it is important to further investigate the multilevel governance, especially the internal and external strength of the intra-city networks in promoting sustainability transitions.

Over the last decade under the same party (Justice and Development Party) rule, Turkey has set ambitious goals, such as becoming the world's 10th largest economy and making Istanbul the world capital of finance and a global city. International networks are essential for knowledge sharing between different spatial scales to achieve such aims. For instance, the national energy efficiency agenda and 
targets literally inspired the IMM into realizing that there is a crucial need to make the city visible in the international arena and enable climate and sustainability funding opportunities by being part of global networks, such as the C40 and ICLEI. The Climate Change Action Plan for Istanbul shows that the IMM complies with the requirements of the global networks by triggering the local public agencies to enable the sustainability transition in Istanbul. Yet, considering that the ongoing plan will be a non-binding document, it raises concerns among urban planners and environmental engineers over the degree to which the plan will be implemented and disseminated in the metropolitan area, as what is implemented is ultimately decided by populist politics. This means that the IMM strategy and planning departments are often regarded as having little real influence on the outcome [69]. Beyond the international networks on climate change and energy efficiency, Istanbul accommodates international financial institutions, such as the International Finance Corporation and European Bank for Reconstruction and Development, which are the supporters of the national energy efficiency agenda. However, we have yet to find evidence that sustainability is being mainstreamed in the building sectors through the collaboration of these global networks' green credentials and start-up environment.

\subsection{Cities and Emerging Niches}

Helsinki has become a national and Nordic hub for the start-up scene. According to Forbes, Helsinki boasts over $10 \%$ of the world's start-up exits, accounting for US\$1 billion in exits per year in the past five years [71]. In terms of sustainability transitions, Helsinki has especially seen the growth of consumer-oriented and business model-based innovations, which aim to create a completely new market or disrupt the existing one. In the long term, these are seeds for radical system transitions for sustainability. The emergence of a strong start-up scene is not surprising, considering Nokia's legacy in information and communication technology, the concentration of universities and the number of highly educated young adults. Yet, it also cannot be taken for granted. It emerged organically from entrepreneurial and bold individuals, but now, the city government also sees it as a competitive advantage. Apart from tech startups, Helsinki has also seen the emergence of many social movements and experiments, such as recycling communities on Facebook, street dining day and sauna day. Thus, new niches are not only commercial, but also based on civil society's mobilization. Importantly, these two components seem to reinforce each other.

For niches to strengthen and create a viable alternative to the regime, they need a seedbed. Cities not only provide an incubation space for the creation of something new, but also a seedbed for experimenting, trying new niches and building user base. The population in Helsinki is younger, more educated, and wealthier compared with the national average. As it is also politically more 'green', user preferences and expectations clearly differ, creating a window of opportunity, especially for consumer-oriented niches. In the energy-efficiency transition, due to the limited financial aid mentioned above, new niches are based on alternative business models, such as energy conservation as a service with monthly fee or a solar panel rental rather than an investment, which would require high upfront payment. Thus, cities provide a critical mass for the uptake of new innovations and the demand for more energy-efficient, environmentally friendly products and services. Nevertheless, cities cannot become sustainable independently [2]; they must be accompanied with sustainability transitions in their surroundings and the remote areas from which they draw resources. The selected emerging startups in Istanbul are not trendsetters for the sustainability transition; they are the followers and implementers of the globally accepted agendas and regulations of energy efficiency, which are imported to Turkey and Istanbul. The start-up environment in Istanbul seemingly aims to increase profit margins, and compliance with energy efficiency appears to be advocated by the companies rather to secure funding than a sense of environmental responsibility. The startups aim to have their products sold mainly to construction companies and citizens and promote their products overseas as soon as they can, as the Turkish market is difficult to break through due to a lack of current interest in green products. 
Entrepreneurs agree that adopting green living is still not conceptualized by customers in Turkey due to the developers' lack of sustainable appliances in their initiated residential projects. As the developers are the ultimate decision makers, using the startups' products to enhance buildings' energy-efficiency levels, and there is no binding legislation for upgrading the energy-efficiency level to $\mathrm{B}$ or $\mathrm{A}$, the entrepreneurs cannot reach out to the individual costumers.

The identified startups already hold their patents, but addressing any infringement of their products represents a serious cost. The entrepreneurs mentioned that if they released their products to the market, the big companies would immediately imitate them without considering the patent infringements. This would cause them to drastically lower the price one the market, and eventually, experience declining revenue from their products. Thus, they are still investing in research and development and making business arrangements with the current urban renewal projects, without sharing the products with the public.

\section{Conclusions}

The explicit role of cities in sustainability transitions has received limited attention. The aim of this paper was to address this gap, especially by analyzing it from a multilevel perspective. The multilevel perspective on sociotechnical regime shifts lacks a dimensional view of different scales that are relevant for sustainability transitions. Cities can operate at the national scale, where they either aim to act as a pioneer and the driving force or merely reproduce the national regime. Cities also operate across scales, for example, through transnational networks. They share ideas and form new sociotechnical regime configurations at the global rather than national scale, as they aim to cooperate and compete with other global cities. Cities aim to provide an incubation space for innovations, experiments, and alternative niches, as well as to give rise to social movements and lifestyle changes. Nevertheless, cities can follow different trajectories and transition dynamics depending on their contextual preconditions and institutional embeddedness. It is important to include the multidimensional scalar relations, as well context-specific variables, for better understanding cities' roles in sustainability transitions.

With this exploratory study, we aimed to highlight the key context-specific variables in the sustainability transition by looking at Helsinki's and Istanbul's energy-efficiency agendas in the housing sector. Although the challenge is shared, it has different characteristics: in contrast to Istanbul, urban renewal in Helsinki is relatively slow, and the challenge has to do with the older houses rather than new buildings. The city of Helsinki has enabled and reinforced the emergence of citizen-led demand for sustainability transition, which differs from the national transition agenda in some cases. How the multilevel governance will play out has yet to be seen. The critical mass in terms of the sustainability transition has been mobilized, but the lack of smart financing mechanisms for long-term energy conservation measures and tripartite flexible cooperation between businesses, local authorities, and residents hinder the fast acceleration of the regime shift. In the case of Istanbul, Turkey is surrounded by international donors and funding institutions, as with its population and economic growth, the country offers lucrative opportunities in return. The large-scale, numerous urban renewal projects in Istanbul offer a window of opportunity, but unfortunately, environmental and social sustainability are not the guiding principles, and civil society is poorly—if at all—engaged and empowered. Moreover, the economic aspirations (becoming the 10th largest economy) hinder the sustainability efforts. For emerging businesses, there are no adequate financial incentives or 'angel investors' in the business environment to allow these businesses to thrive. Also, the qualitative data suggested that due to the developers' lack of interests to include sustainable appliances in their residential projects inhibits the culture of green lives to grow among customers in Istanbul. Thereof, the absence of green consumerism in the residential market of Istanbul constrains locals in conceptualizing green development in their housing units. Such factors indicate that transition research for Istanbul only portrays the prevailing socioeconomic-political and cultural structures. Comparing the two cities enabled us to structure our sustainability analysis along three dimensions, and each dimension reflected case-specific outcomes that broadened our analysis for future studies. 


\subsection{City-Nation Regime Dynamics}

Helsinki and Istanbul both aim to be carbon-neutral, energy-efficient cities, and their global ties and mobile policies in energy efficiency are compatible; yet, various factors, such as public participation, local autonomy, and national institutions' domination over local ones, are the ones that differentiate the implementation and dissemination of the same goals. The two cases imply that the transition to sustainability requires structural changes, and therefore, the hindering and facilitating factors for sustainable transitions at different spatial scales must be identified. In the case of Helsinki, municipalities have more maneuvering space, and Helsinki has implemented voluntary actions; yet, in terms of coercive action, the city level depends on the EU- and national-level policies. However, the city has taken a more active role in recent years, especially in strengthening its local governance and strategic action, in contrast to the national level. For Istanbul, the nation's domination over local municipalities has caused maladaptation in the sustainability transition. Therefore, the most fragile socioecological and sociotechnical services in the local areas due to populist political interventions must be identified for future urban transition analysis. This indicates that urban transition research should widen the scope of analysis in urban areas. In our research, in addition to energy efficiency in buildings, the sustainability of mobility, energy supply, food, and goods and services in the urban context would say more about the relativeness of the national government's position over the local's ability for transition. This can be done by further delineating city-national regime dynamics at the levels of the local authority's decision-making power (hard and soft), local participation in the transition, the degree to which the local transition vision differs from the national one, and whether the local authority has executive and enforcing power.

\subsection{Cities and Global Networks}

Both the government's and local municipalities' energy-efficiency agendas seem compatible with the global networks' push toward climate and energy efficiency. Especially for the case of Helsinki, both local intra-city and international networks have been used as tools to leverage the agency over the transition nationally and stand out internationally. This is supported by the recent policy strategy. Within this picture, the tangible outcomes for generating more positive environmental and social effects are yet to come for the Istanbul case. This collaborative force between the global networks and city is ongoing, and it may lead the city into more sustainable trajectories, and eventually, more entrepreneurial, financial, political, and social efforts to invest in energy efficiency. The lack of visionary preparedness for sustainability along with the economic growth aspirations in Turkey and the absence of successful low-carbon initiatives to feed confidence to the national and local economy might count as hindering factors, which disenabled the strong environmental and social effects in the city so-far. Further questions to be investigated arise: To what extent do the networks operate for internal sharing and learning of best practices? To what extent do they aim to claim agency externally among the international agenda? To what extent do prestigious networks enhance the mobilization of financing, young talent, and local commitment and empowerment? Finally, to what extent is the transition vision shared among the partners in the networks, or are there dissonances?

\subsection{Cities and Emerging Niches}

In the past five years, Helsinki has become a Nordic start-up hub, and now, the city also aims to support this in various ways, for example, by providing office spaces, supporting experiments and collaborating. The city has also actively supported civic movements and engagement in local decision making, which reinforce niche alignment and dissemination. Niches and startups have not explicitly focused on energy-efficiency issues; rather, they have considered a broader sustainability vision and radical transformations, while changing user preferences and expectations. Thus, Helsinki offers not only an incubation space and seedbed for novelties, but also the critical mass and market demand for more sustainable alternatives. 
The emerging new niches in Istanbul seem consonant with the city's energy efficiency agenda; yet, the city does not directly offer support to improve these new businesses' models to fulfil the city's needs. The lack of collaboration and unity between the city administration and emerging businesses hinders the dissemination of so-called innovative products, making them invisible in the city's territory. In addition to the local administration, there is also a lack of appreciation from the locals, as customers of these products. Therefore, the existing knowledge systems of the locals concerning the energy efficiency agenda remains an issue of concern for the entrepreneurs. In terms of the niche dynamics in a city, the following questions require further investigation: To what extent do types of emerging niches, in terms of radicalness, consumer versus production orientation, business model and entrepreneurial motivation, play a role in the sustainability transition? To what degree do niches arise from local needs and expectations or imitate global trends? To what degree do cities benefit from such niche and start-up activity? Finally, to what degree is financing available locally, nationally, and internationally?

Author Contributions: Conceptualization, A.K. and M.Y.; Methodology, A.K. and M.Y.; Data collection and analysis-Helsinki, A.K.; Data collection and analysis-Istanbul, M.Y.; Writing-Original Draft Preparation, A.K. and M.Y.; Writing-Review and Editing, A.K. and M.Y.

Funding: The Istanbul case of this research is supported by EU Horizon 2020 GREEN-WIN Project (642018).

Conflicts of Interest: The authors declare no conflict of interest.

\section{References}

1. United Nations (UN). World Urbanization Prospects—The 2014 Revision; United Nations (UN): New York, NY, USA, 2014.

2. Rees, W.; Wackernagel, M. Urban ecological footprints: Why cities cannot be sustainable-And why they are a key to sustainability. Environ. Impact Assess. Rev. 1996, 16, 223-248. [CrossRef]

3. UN-Habitat. Urbanization and Development: Emerging Futures; United Nations Human Settlements Programme (UN-Habitat): Nairobi, Kenya, 2016.

4. Bettencourt, L.; Lobo, J.; Strumsky, D. Invention in the city: Increasing returns to patenting as a scaling function of metropolitan size. Res. Policy 2007, 36, 107-120. [CrossRef]

5. Hertwich, E.; Peters, G. Carbon footprint of nations: A global, trade-linked analysis. Environ. Sci. Technol. 2009, 43, 6414-6420. [CrossRef] [PubMed]

6. Seyfang, G.; Haxeltine, A.; Hargreaves, T.; Longhurst, N. Energy and Communities in Transition: Towards a New Research Agenda on Agency and Civil Society in Sustainability Transitions; Environmental Decision Making, University of East Anglia: Norwich, UK, 2010.

7. Mindali, O.; Raveh, A.; Salomon, I. Urban density and energy consumption: A new look at old statistics. Transp. Res. Part A Policy Pract. 2004, 38, 143-162. [CrossRef]

8. Wiedmann, T.O.; Schandl, H.; Lenzen, M.; Moran, D.; Suh, S.; West, J.; Kanemoto, K. The material footprint of nations. Proc. Natl. Acad. Sci. USA 2015, 112, 6271-6276. [CrossRef] [PubMed]

9. Weinzettel, J.; Hertwich, E.G.; Peters, G.P.; Steen-Olsen, K.; Galli, A. Affluence drives the global displacement of land use. Glob. Environ. Chang. 2013, 23, 433-438. [CrossRef]

10. Markard, J.; Raven, R.; Truffer, B. Sustainability transitions: An emerging field of research and its prospects. Res. Policy 2012, 41, 955-967. [CrossRef]

11. Coenen, L.; Benneworth, P.; Truffer, B. Toward a spatial perspective on sustainability transitions. Res. Policy 2012, 41, 968-979. [CrossRef]

12. Geels, F. From sectoral systems of innovation to socio-technical systems: Insights about dynamics and change from sociology and institutional theory. Res. Policy 2004, 33, 897-920. [CrossRef]

13. Smith, A.; Voss, J.-P.; Grin, J. Innovation studies and sustainability transitions: The allure of the multi-level perspective and its challenges. Res. Policy 2010, 39, 435-448. [CrossRef]

14. Geels, F.; Schot, J. Typology of sociotechnical transition pathways. Res. Policy 2007, 36, 399-417. [CrossRef]

15. Geels, F. Ontologies, socio-technical transitions (to sustainability), and the multi-level perspective. Res. Policy 2010, 39, 495-510. [CrossRef]

16. Hodson, M.; Marvin, S. Can cities shape socio-technical transitions and how would we know if they were? Res. Policy 2010, 39, 477-485. [CrossRef] 
17. Naess, P.; Vogel, N. Sustainable urban development and the multi-level transition perspective. Environ. Innov. Soc. Transit. 2012, 4, 36-50. [CrossRef]

18. Nevens, F.; Frantzeskaki, N.; Gorissen, L.; Loorbach, D. Urban transitions labs: Co-creating transformative action for sustainable cities. J. Clean. Prod. 2013, 50, 111-122. [CrossRef]

19. Bulkeley, H.; Broto, V.; Hodson, M.; Marvin, S. Cities and Low Carbon Transitions; Routledge Studies in Human Geography: Abingdon, UK, 2010.

20. Betsill, M.; Bulkeley, H. Looking back and thinking ahead: A decade of cities and climate change research. Int. J. Justice Sustain. 2007, 12, 447-456. [CrossRef]

21. Smith, A.; Stirling, A.; Berkhout, F. The governance of sustainable socio-technical transitions. Res. Policy 2005, 34, 1491-1510. [CrossRef]

22. Dyllick, T.; Muff, K. Clarifying the meaning of sustainable business: Introducing a typology from business-as-usual to true business sustainability. Organ. Environ. 2016, 29, 156-174. [CrossRef]

23. Keiner, M.; Kim, A. Transnational city networks for sustainability. Eur. Plan. Stud. 2007, 15, 1369-1395. [CrossRef]

24. Kern, K.; Bulkeley, H. Cities, Europeanization and multi-level governance: Governing climate change through transnational municipal networks. JCMS J. Common Mark. Stud. 2009, 47, 309-322. [CrossRef]

25. Ornetzeder, M.; Rohracher, H. Of solar collectors, wind power, and car sharing: Comparing and understanding successful cases of grassroots innovations. Glob. Environ. Chang. 2013, 23, 856-867. [CrossRef]

26. Geels, F.W.; Kern, F.; Fuchs, G.; Hinderer, N.; Kungl, G.; Mylan, J.; Neukirch, M.; Wassermann, S. The enactment of socio-technical transition pathways: A reformulated typology and a comparative multi-level analysis of the German and UK low-carbon electricity transitions (1990-2014). Res. Policy 2016, 45, 896-913. [CrossRef]

27. Anguelovski, I.; Chu, E.; Carmin, J. Variations in approaches to urban climate adaptation: Experiences and experimentation from the global South. Glob. Environ. Chang. 2014, 27, 156-167. [CrossRef]

28. Vogel, B.; Henstra, D. Studying local climate adaptation: A heuristic research framework for comparative policy analysis. Glob. Environ. Chang. 2015, 31, 110-120. [CrossRef]

29. Georgeson, L.; Maslin, M.; Poessinouw, M.; Howard, S. Adaptation response to climate change differ between global megacities. Nat. Clim. Chang. 2016, 6, 584-588. [CrossRef]

30. Robinson, J. Comparative urbanism: new geographies and cultures of theorizing the urban. Int. J. Urban Reg. Res. 2015, 40, 187-199. [CrossRef]

31. Kaupunkitutkimus. Helsingin Seudun Toimialarakenne. Available online: http:/ www.kaupunkitutkimusta. fi/toimialakatsaukset/helsingin-seudun-toimialakatsaus/ (accessed on 15 January 2018).

32. European Commission. SBE Fact Sheet-Turkey. 2017. Available online: https://ec.europa.eu/ neighbourhood-enlargement/sites/near/files/turkey_sba_fs_2017.pdf (accessed on 13 December 2017).

33. Baabou, W.; Grunewald, N.; Ouellet-Plamondon, C.; Gressot, M.; Galli, A. The ecological footprint of Mediterranean cities: Awareness creation and policy implications. Environ. Sci. Policy 2017, 69, 94-104. [CrossRef]

34. Helsinki Environmental Statistics. Available online: http://www.helsinginymparistotilasto.fi/Dialog/ SaveShow.asp (accessed on 15 January 2018).

35. Maija, M.; Marja, S.; Olli, S.; Juhani, H.; Tuuli, M.; Riina, A.; Seppälä, J. Kuntien Resurssiviisauden Indikaattorit (Indicators for Resource Smart Municipalities); Environmental Institute of Finland (SYKE): Helsinki, Finland, 2015.

36. IEA (International Energy Agency). Energy Policies of IEA Countries, Turkey 2016 Review; OECD/IEA: Paris, France, 2016; Available online: https://www.iea.org/publications/freepublications/publication/ EnergyPoliciesofIEACountriesTurkey.pdf (accessed on 14 November 2017).

37. Republic of Turkey. National Climate Change Action Plan (NCCAP) for 2011-2023. Available online: http:/ / www.dsi.gov.tr/docs /iklim-degisikligi/ \T1 \idepeng.pdf?sfvrsn=2 (accessed on 11 November 2017).

38. World Bank. Republic of Turkey: Institutional Review of Energy Efficiency; The World Bank Group: Washington, DC, USA, 2015.

39. NEEAP. Turkey's National Energy Efficiency Action Plan; NEEAP: Ankara, Turkey, 2017. (In Turkish)

40. International Energy Agency and Nordic Energy Research. Nordic Energy Technology Perspectives; OECD: Paris, France, 2016. 
41. Statistics Finland. Asumisen Energiakulutus. 2012. Available online: https://www.stat.fi/til/asen/index. html (accessed on 10 January 2018).

42. NEEAP. Suomen Kansallinen Energiatehokkuuden Toimintasuunnitelma NEEAP-4; NEEAP: Helsinki, Finland, 2017. (In Finnish)

43. HSY. Helsinki Metropolitan Area Climate Change Adaptation Strategy; Helsinki Regional Environmental Services Authority: Helsinki, Finland, 2012.

44. McKinsey \& Company. Pathways to a Low Carbon Economy: Version 2 of the Global Greenhouse Gas Abatement Cost Curve; McKinsey \& Company: New York, NY, USA, 2009.

45. Geller, H.; Harrington, P.; Rosenfeld, A.H.; Tanishima, S.; Unander, F. Policies for increasing energy efficiency: Thirty years of experience in OECD countries. Energy Policy 2006, 34, 556-573. [CrossRef]

46. European Commission. Available online: http://europa.eu/rapid/press-release_MEMO-16-3986_en.htm (accessed on 15 January 2018).

47. Sovacool, B. Contestation, contingency, and justice in the Nordic low-carbon energy transition. Energy Policy 2017, 102, 569-582. [CrossRef]

48. HSY. Ilmastoviisas Asuminen; HSY: Helsinki, Finland, 2016. (In Finnish)

49. Monni, S.; Raes, F. Multi-level climate policy: The case of the European Union, Finland and Helsinki. Environ. Sci. Policy 2008, 11, 743-755. [CrossRef]

50. Energiatehokkuussopimukset 2017-2025. Available online: http:/ /www.energiatehokkuussopimukset20172025.fi/energiatehokkuussopimukset/ (accessed on 15 January 2018).

51. Motiva. Available online: https://www.motiva.fi/ratkaisut/energiatehokkuussopimukset (accessed on 15 January 2018).

52. Rönty, J.; Paiho, S. Rahoitusratkaisujen Asuinrakennusten Perusparannuksiin ja Energiakorjauksiin; VTT: Espoo, Finland, 2012. (In Finnish)

53. Lahtinen, H.; Pekkala, H.; Halme, K.; Salminen, V.; Harmala, V.; Wikeri, J.; Lammikoski, H.; Lahde, K.; Mikkela, K.; Rouvinen, P.; et al. Growth Factors and Bottlenecks for Business Start-Ups; Publications of the Government's Analysis, Assessment and Research Activities 30/2016; Prime Minister's Office: Helsinki, Finland, 2016.

54. OECD. Primary Energy Supply (Indicator); OECD: Paris, France, 2018. [CrossRef]

55. Turkey's Strategic Vision for 2023. Available online: http://tsv2023.org/pdf/tsv2023_rapor1.pdf (accessed on 25 January 2018). (In Turkish)

56. Tagliapietra, S.; Zachmann, G. A New Strategy for European Union-Turkey Energy Cooperation. Available online: http:/ / bruegel.org/wp-content/uploads/2017/10/PC-27-2017.pdf (accessed on 25 January 2018).

57. UNDP. Promoting Energy Efficiency in Buildings in Turkey; UNDP: Ankara, Turkey, 2010.

58. ECOFYS. U Value Maps of Turkey. Available online: https:/ /www.ecofys.com/files/files/ecofys-2016-uvalue-maps-turkey.pdf (accessed on 25 November 2017).

59. BEP-TR (Binalarda Enerji Verimliliği Performansı). Available online: http://www.bep.gov.tr/BEPTRWEB/ Default.aspx\#.Wm2YFq2B2jQ (accessed on 2 January 2018).

60. Turk Stat (Turkish Statistical Institute). Building Permits Statistics and Percentage Changes. 2018. Available online: www.tuik.gov.tr/PreIstatistikTablo.do?istab_id=1558 (accessed on 1 January 2018).

61. Turk Stat (Turkish Statistical Institute). Population and Housing Census. 2011. Available online: http:/ / www.turkstat.gov.tr/Kitap.do?metod=KitapDetay\&KT_ID=11\&KITAP_ID=276 (accessed on 21 October 2017).

62. Turk Stat (Turkish Statistical Institute). Quarterly Gross Domestic Product Press Release. 2017. Available online: http: / / www.turkstat.gov.tr / PreHaberBultenleri.do?id=24566 (accessed on 1 January 2018).

63. IMSP (Istanbul Metropolitan Strategic Plan for 2015-2019). Available online: http://www.ibb.gov.tr/enUS/Organization/Birimler/StratejikPlanlamaMd/Documents/stratejik_plan_2015-2019.pdf (accessed on 28 December 2017).

64. ICCAP. Istanbul Climate Change Action Plan 2016-2018. Available online: http:/ / climate.istanbul (accessed on 27 December 2017).

65. GEF (Global Environment Facility). Small and Medium Enterprise Energy Efficiency Project. Available online: https:/ / www.thegef.org/project/small-and-medium-enterprise-energy-efficiency-project (accessed on 27 October 2017). 
66. Çetik, M. The Governance of Standardisation in Turkish Green Building Certification Schemes. SSRN Working Document. 2014. Available online: https:/ / papers.ssrn.com/sol3/papers.cfm?abstract_id=2435160 (accessed on 30 March 2017).

67. Ünal, B. Sustainable Development of Istanbul Built Environment. Master's Thesis, KTH, Architecture and the Built Environment, Stockholm, Sweden, 2014. Available online: http:/ / www.diva-portal.org/smash/ get/diva2:731291/FULLTEXT01.pdf (accessed on 25 November 2017).

68. Poucher Harbin, J. Rethinking Global Cities: Why Istanbul Is a Success for Some and Urban Plunder for Others. Available online: http:/ / islamicommentary.org/2015/02/rethinking-global-cities-why-istanbulis-a-success-for-some-urban-plunder-for-others / (accessed on 2 December 2017).

69. Erder, S. Local Governance in Istanbul. Available online: https://lsecities.net/media/objects/articles/localgovernance-in-istanbul/en-gb/ (accessed on 12 January 2018).

70. City of Helsinki. Maailman Toimivin Kaupunki-Helsingin Kaupunkistrategia 2017-2021; City of Helsinki: Helsinki, Finland, 2017.

71. Armstrong, P. Here's how the Nordics get $10 \%$ of all the startup exits in the world. Forbes 2017, $21,7$.

(C) 2018 by the authors. Licensee MDPI, Basel, Switzerland. This article is an open access article distributed under the terms and conditions of the Creative Commons Attribution (CC BY) license (http:/ / creativecommons.org/licenses/by/4.0/). 